\title{
INVASÃO E MANEJO DE Pinus taeda EM CAMPOS DE ALTITUDE DO PARQUE ESTADUAL DO PICO PARANÁ, PARANÁ, BRASIL
}

\author{
Renan Macari Falleiros ${ }^{1}$, Rafael Dudeque Zenni ${ }^{2}$, Sílvia Renate Ziller ${ }^{3}$ \\ ${ }^{1}$ Biólogo, Curitiba, PR, Brasil - renanfalleiros@hotmail.com \\ ${ }^{2}$ Eng. Florestal, Esp., Instituto Hórus de Desenvolvimento e Conservação Ambiental, Curitiba, PR, Brasil - rafaeldz@ gmail.com \\ ${ }^{3}$ Eng $^{\mathrm{a}}$ Florestal, Dr ${ }^{\mathrm{a}}$., Instituto Hórus de Desenvolvimento e Conservação Ambiental, Curitiba, PR, Brasil - \\ contato@institutohorus.org.br
}

Recebido para publicação: 14/09/2009 - Aceito para publicação: 29/04/2010

\begin{abstract}
Resumo
Espécies exóticas invasoras são espécies introduzidas e estabelecidas que produzem descendentes viáveis e que se propagam a distâncias significativas da planta-mãe, podendo causar danos ao meio ambiente. O presente estudo teve como objetivo realizar as primeiras avaliações sobre esse processo de invasão e uma ação de manejo da planta exótica invasora Pinus taeda em três morros no Parque Estadual do Pico Paraná, Paraná, Brasil. O manejo foi realizado mecanicamente, com corte das plantas, e as primeiras respostas sobre a cobertura vegetal e a riqueza de espécies foram mensuradas dez meses após a ação de corte. Os resultados indicam que a população da espécie invasora no local do estudo tem aproximadamente 36 anos, que as plantas crescem num ritmo inferior à média de outros ambientes, que sob a influência de pínus a vegetação nativa apresentou menor porcentagem de cobertura e, finalmente, que após o corte e derrubada de pínus a vegetação apresentou menor riqueza. O manejo teve custo total de R\$199,00 por hectare. Concluiu-se que os campos de altitude são habitats suscetíveis a invasão biológica por pínus e que o período de 10 meses foi insuficiente para se obterem conclusões consistentes sobre o controle mecânico por corte raso.

Palavras-chave: Espécies exóticas invasoras; invasão biológica; Pinus taeda; Campos de Altitude; Parque Estadual do Pico Paraná.
\end{abstract}

\begin{abstract}
Invasion and managment of Pinus taeda in mountain top grasslands of Pico Paraná State Park, Paraná, Brazil. Invasive alien species are introduced from other ecosystems and establish, producing viable descendency that spread for significant distances from the mother plants, potentially cause damage to the environment. The aim of the current study is to evaluate the first responses of the invasion process and the results of Pinus taeda control on three mountain areas in the Pico Paraná State Park, Southern Brazil. The control was conducted mechanically by felling adult trees and pulling out seedlings. The first responses were measured ten months after felling, measuring plant coverage and species richness. Results indicate that the population of invasive pines in these areas is around 36 years old, growing at a slower rate when compared to the average growth in other habitats, that the pine trees impact the native vegetation by producing lower coverage and finally, that after felling the pine trees the native vegetation showed lower richness. The control method had a cost of R \$ 199,00 (about US\$ 100) per hectare. Conclusions are that high mountain grasslands are susceptible habitats for biological invasion by pine trees and that recurrent work needs to be done for more consistent elucidations.
\end{abstract}

Keywords: Invasive alien species; biological invasion; Pinus taeda; grasslands; Atlantic Forest; invasive conifers.

\section{INTRODUÇÃO}

Espécies exóticas são aquelas que ocorrem fora da sua área de ocorrência historicamente conhecida, por consequência de um processo de movimentação acidental ou intencional via assistência humana. Espécies exóticas invasoras são espécies introduzidas e estabelecidas que produzem descendentes viáveis e que se propagam a distâncias significativas da planta-mãe (RICHARDSON et al., 2000 , sugere $>100 \mathrm{~m}$ em 50 anos para plantas que se reproduzem por sementes), podendo causar danos ao 
meio ambiente (PYŠEK; RICHARDSON, 2008; DAVIS, 2009). Há exemplos de espécies invasoras que alteraram a sobrevivência e permanência de espécies nativas por exclusão competitiva, deslocamento de nichos, hibridação, predação e, em casos extremos, extinção local (MOONEY; CLELAND, 2001).

A invasão biológica em ecossistemas naturais por coníferas foi documentada inicialmente na África do Sul em 1855, depois na Nova Zelândia em 1880 e na Austrália em 1950 (SIMBERLOFF et al., 2009). Desde então, essas espécies (em particular o gênero Pinus L.) se espalharam até se tornarem um dos maiores problemas ambientais nesses locais (RICHARDSON et al., 2008; SIMBERLOFF et al., 2009). O gênero Pinus está, sem dúvida, entre os gêneros mais importantes para silvicultura nos trópicos e subtrópicos (RICHARDSON, 1998), porém também representa algumas das espécies com o maior potencial de invasão de ambientes naturais (ZALBA et al., 2008). Entre os principais aspectos que têm sido relacionados com o sucesso das invasões biológicas de Pinus no hemisfério Sul estão a dispersão das sementes pelo vento, períodos juvenis curtos, pequenos intervalos de tempo entre safras de alta produtividade de sementes, longo tempo de residência nas áreas onde foi introduzido e o cultivo intensivo (HIGGINS; RICHARDSON, 1998).

No Brasil, o gênero Pinus está presente desde 1880, e em 1936 foram iniciados os primeiros experimentos com fins silviculturais nas regiões Sul e Sudeste, com Pinus taeda L. e P. elliottii Engelm. (SHIMIZU, 2006). Desde então, foram registradas invasões nos campos gerais (Estepe GramíneoLenhosa) no Paraná e em Santa Catarina (ZILLER, 2001), no cerrado em São Paulo (MAHMOUD et al., 2003; PIVELLO, 2005), na restinga (Formações Pioneiras de Influência Marinha) em Santa Catarina (BECHARA, 2003), nos pampas (Estepe) no Rio Grande do Sul (ABREU, 2006) e nos campos de altitude (Refúgios Vegetacionais) no Paraná (MOCOCHINSKI, 2006; VASHCHENKO et al., 2007; SIMÃO, 2008), sempre em formações vegetacionais abertas com predomínio de gramíneas e arbustos ou árvores esparsas, assim como em áreas de formações florestais onde tenha havido desmatamento.

Os campos de altitude (Refúgios Vegetacionais, segundo IBGE, 1992) são habitats inseridos no bioma Mata Atlântica da Serra do Mar, localizados nos cumes dos morros, em altitudes superiores a $1.060 \mathrm{~m}$ (MOCOCHINSKI, 2006). Formam-se em condições ambientais peculiares, decorrentes de efeitos da altitude e do relevo acidentado e que, devido ao isolamento das populações, apresentam elevados níveis de endemismo (SAFFORD, 1999; MOCOCHINSKI et al., 2008). Esses ambientes são importantes não só pelo seu significado biológico e geológico, mas principalmente porque representam as primeiras áreas de estoque de água e de drenagem para o suprimento de água de quase $25 \%$ da população brasileira (SAFFORD, 1999).

Assim, o presente estudo teve como objetivo avaliar uma invasão de Pinus taeda e a influência da ação de manejo mecânico sobre a riqueza e abundância da cobertura vegetal nativa dos campos de altitude, decorridos dez meses da ação de corte, no Parque Estadual do Pico Paraná, na região dos morros Tucum, Camapuã e Camacuã.

\section{MATERIAL E MÉTODOS}

\section{Caracterização da área de estudo}

O trabalho foi realizado no conjunto dos picos Camacuã, Camapuã e Tucum $(1.550 \mathrm{~m}, 1.706 \mathrm{~m}$ e $1.736 \mathrm{~m}$ de altitude, respectivamente), na porção sudoeste do Parque Estadual do Pico Paraná, localizado na Serra do Ibitiraquire, nos municípios de Campina Grande do Sul e Antonina, estado do Paraná $\left(25^{\circ} 15^{\prime} 18^{\prime \prime} \mathrm{S}\right.$ e $\left.48^{\circ} 51^{\prime} 30^{\prime \prime} \mathrm{O}\right)$. As avaliações e ações foram realizadas exclusivamente na porção dos campos de altitude (Figura 1). Duas classes de solos são encontradas nas regiões altomontanas: Neossolos Litólicos e Organossolos. Nas áreas de ocorrência dos campos de altitude, raramente são encontradas classes de solos diferente das citadas (MOCOCHINSKI, 2006). Segundo a classificação de Köppen, o clima é temperado - $\mathrm{Cfb}$-, caracterizado por temperatura média no mês mais frio abaixo de $18^{\circ} \mathrm{C}$ (mesotérmico), com verões frescos, temperatura média no mês mais quente abaixo de $22{ }^{\circ} \mathrm{C}$ e sem estação seca definida (IAPAR, 1994).

\section{Caracterização da população de Pinus taeda}

Foram coletados dados morfológicos (área da copa, altura e diâmetro à altura do peito), idade (contagem de anéis de crescimento), coordenadas geográficas (com GPS) e fitofisionomia (seguindo MOCOCHINSKI, 2006) de 238 árvores de pínus numa área de aproximadamente 14,4 ha nos morros Camapuã e Camacuã. Essa amostra representa 10\% das plantas de pínus encontradas e 6,4\% da área total 
do projeto. Essas informações foram usadas para se verificar a existência de um padrão de distribuição espacial, indicadores da existência de ambientes mais ou menos suscetíveis a invasão e a taxa de crescimento de Pinus taeda. O padrão espacial foi avaliado visualmente, com registro da localização geográfica das árvores e das respectivas idades e tamanhos em software de sistema de informações geográficas - SIG (Arcview ${ }^{\circledR}$ 3.2a). A taxa de crescimento dos indivíduos amostrados foi determinada por regressão linear entre a idade e a altura das árvores, e então comparada às taxas de crescimento da mesma espécie em outros locais. Todos os indivíduos identificados na área eram da espécie Pinus taeda, o que não descarta a possibilidade de haver outras espécies do gênero invadindo a área.

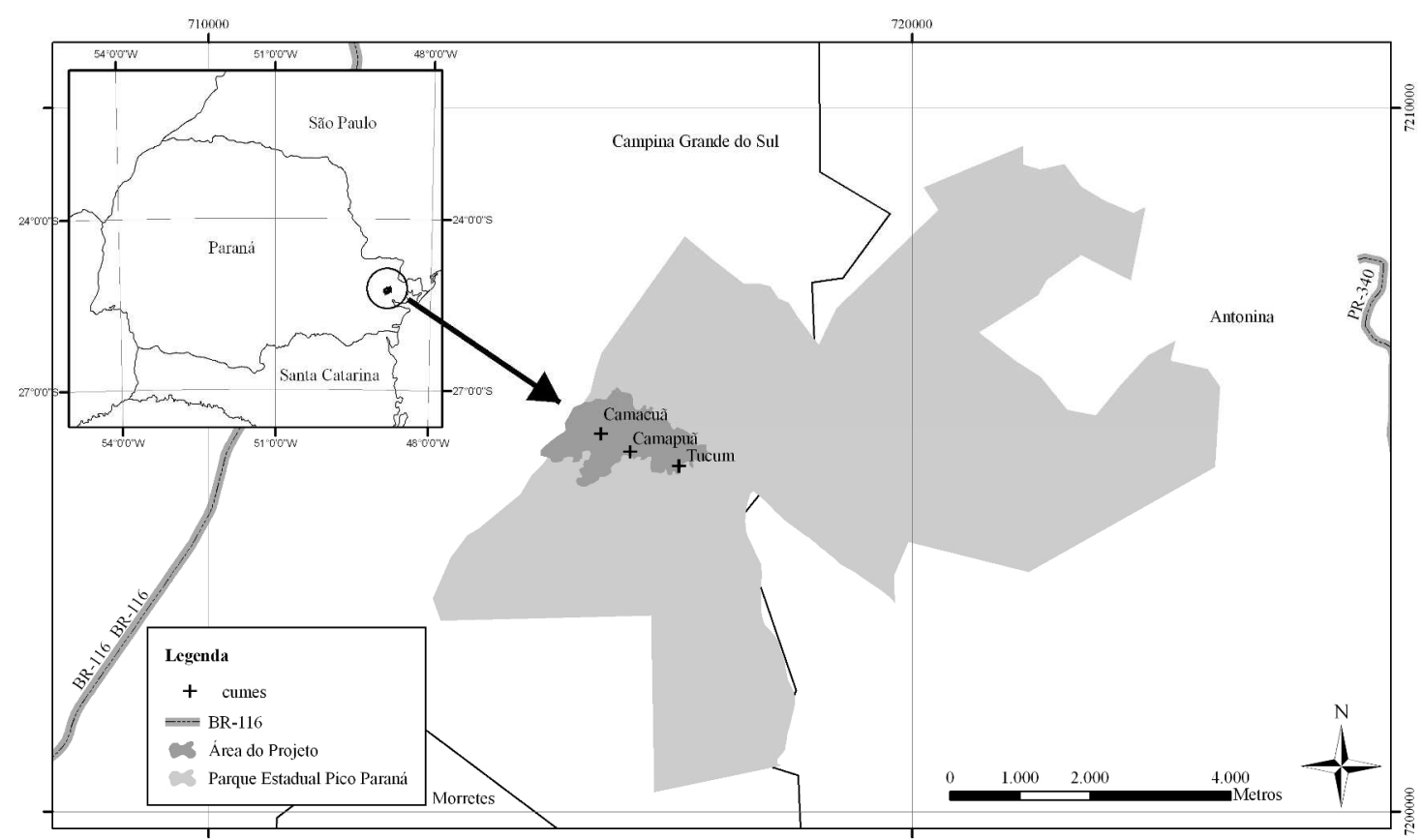

Figura 1. Campos de altitude dos morros Tucum, Camapuã e Camacuã (área de abrangência do projeto,

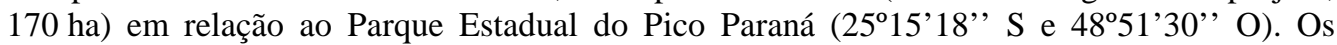
cumes dos morros estão indicados por + .

Figure 1. Mountain top grasslands of Tucum, Camapuã and Camacuã (project area, 170 ha) in the context of the Pico Paraná State Park (25 $15^{\prime} 18^{\prime \prime}$ S e 48 51'30' O). The mountain tops are pointed out by $\mathrm{a}+$.

\section{Ação de manejo}

As árvores de pínus encontradas foram cortadas por uma equipe de quatro pessoas, de acordo com as recomendações de Cuevas (2005): corte raso $(10 \mathrm{~cm}$ de altura) e extração das gêmulas e galhos abaixo disso. As árvores maiores foram cortadas com motosserra (modelo Stihl ${ }^{\circledR} 210$ e 250 ) e as plântulas e plantas jovens foram arrancadas do solo com raiz e parte aérea ou cortadas rente ao solo com facão. $\mathrm{O}$ trabalho foi iniciado nas áreas mais longínquas dos plantios que configuram a fonte da invasão, no morro Tucum, seguindo em direção ao núcleo da população, no morro Camapuã, e em seguida ao morro Camacuã.

As árvores foram derrubadas na direção que causasse menor dano aparente à vegetação nativa circundante. Os restos das plantas foram deixados no local, em função da impossibilidade logística de sua retirada e arraste morro abaixo. As árvores grandes foram desgalhadas e o caule cortado em segmentos menores, para diminuir o sombreamento sobre a vegetação herbácea nativa e para facilitar a decomposição da madeira pelo contato com o solo.

Todos os custos com material, deslocamento e estadia nas montanhas foram contabilizados, assim como o tempo de trabalho em cada área. $\mathrm{O}$ custo por hectare foi calculado dividindo-se o valor total do projeto pela área coberta pelo trabalho. 
Efeitos da presença e do manejo de Pinus taeda sobre a riqueza e abundância de espécies nativas

Para avaliar as primeiras respostas da vegetação nativa dos campos de altitude sobre o manejo mecânico de Pinus taeda, foram estabelecidos três tratamentos, em parcelas amostrais de $100 \mathrm{~m}^{2}$ cada: (i) área não manejada e com a presença de Pinus taeda (COM PINUS); (ii) área onde se procedeu ao corte de Pinus taeda, nas condições acima descritas (MANEJO); e (iii) área com vegetação de campos de altitude sem presença de espécies exóticas invasoras (TESTEMUNHA). As parcelas foram instaladas na face nordeste do morro Camacuã, com aproximadamente $100 \mathrm{~m}$ de distância entre elas. A área selecionada apresenta declividade, altitude e cobertura vegetal visualmente homogênea. O tempo decorrido desde o corte de $P$. taeda no tratamento MANEJO e desde a coleta de dados até a mensuração dos resultados foi de 10 meses.

A coleta de dados após o manejo foi realizada nos meses de março e abril de 2009, utilizando-se o método de parcelas dispostas em linhas, com 50 parcelas de $2 \mathrm{~m}^{2}$ para cada tratamento. Para cada espécie nativa foram anotados os valores de riqueza e de percentagem de cobertura em cada parcela, a partir da adaptação do método de Muller-Dombois-Ellenberg (1974). Nos tratamentos COM PINUS e MANEJO foi estimada também a proporção de área coberta por troncos de Pinus taeda recém-cortados (tronco) e/ou por acículas de P. taeda.

Exemplares das espécies nativas foram coletados, herborizados e, posteriormente, identificados em laboratório, através de comparações com material do Herbário da Universidade Federal do Paraná (UPCB) e consultas a especialistas. A organização das famílias fundamentou-se no sistema Angiosperm Phylogenetic Groups - APG II (APG 2003). As espécies foram, posteriormente, categorizadas, de acordo com a forma de vida, em herbácea, lianescente, arbustiva ou arbórea. Para efeitos de análise, as formas de vida foram agrupadas em herbáceas (ervas e lianas herbáceas) e arbustivo-arbóreas (arbustos e árvores).

$\mathrm{Na}$ análise testou-se a hipótese de que a riqueza de espécies e a cobertura vegetal são maiores nos tratamentos TESTEMUNHA, MANEJO e COM PINUS, respectivamente. Para tanto, foram calculadas as médias dessas variáveis e realizadas análises de variância (ANOVA) e o teste de TukeyKramer a posteriori (ZAR, 1999). Em todos os casos, os valores foram transformados (log ou

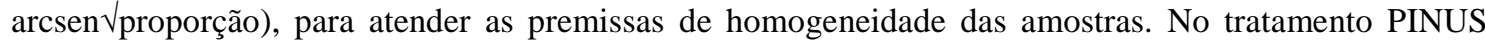
também foi testada a existência de relação entre o grau de cobertura por troncos e acículas e a riqueza de espécies nativas, através de correlações Spearman (ZAR, 1999).

\section{RESULTADOS E DISCUSSÃO}

\section{Caracterização da população de Pinus taeda}

Os propágulos de Pinus taeda que estão invadindo os campos de altitude são provenientes de pequenos plantios comerciais na base dos morros, em propriedades particulares. A árvore mais velha encontrada tinha 36 anos de idade, assumindo-se ser aproximadamente este o tempo de existência da invasão. A densidade média estimada foi de 10 plantas por hectare, variando de áreas sem invasão até áreas densamente invadidas, com cerca de 700 plantas por hectare.

A taxa de crescimento médio em altura encontrada foi de $0,68 \mathrm{~m}$ por ano $(\mathrm{y}=-0.13166+$ $0.6838 * x ; p<0,001$; onde y representa a altura das plantas em função da idade $x$; Figura 2) e indica um crescimento significativamente menor do que o valor médio de $1,4 \mathrm{~m} /$ ano encontrado em outras áreas do Paraná, conforme apresentado, por exemplo, em Andrade (2006) e Baldanzi et al. (1974). Supõe-se que a menor taxa de crescimento de Pinus taeda em relação a outros ambientes no estado do Paraná se deva às condições ambientais das encostas e topos de morros na Serra do Mar, de solos orgânicos ou litólicos rasos e com ventos fortes e constantes, entre outros fatores (TRAMUJAS, 2000). Contudo, embora condições edafoclimáticas restritivas diminuam a taxa de crescimento das plantas, elas não impedem o seu desenvolvimento e reprodução, e nem o aumento gradativo da população.

Não foi possível detectar um padrão de dispersão em que as plantas mais velhas estariam mais próximas das fontes de sementes e as plantas comparativamente mais jovens estariam em áreas gradativamente mais distantes das fontes de propágulos. A distribuição das plantas com mesma idade é aparentemente aleatória. Em um experimento realizado para avaliação de mecanismos envolvidos em dispersão de sementes anemocóricas, foi observada uma distância de dispersão para Pinus taeda de até 200 metros em uma área de floresta com densidade média de 311 árvores/ha (NATHAN et al., 2002). Embora não tenham sido encontradas referências de dispersão de sementes de pínus em áreas abertas, é 
possível supor que, livres de barreiras físicas, as sementes podem disseminar-se a maiores distâncias e em mais direções. Regimes de ventos inconstantes e eventualmente intensos podem levar sementes a grandes distâncias, o que cria novos focos de invasão distantes da fonte inicial. O modelo de invasão de "dispersão em franja" proposto por Ledgard (2001) se aplica parcialmente na situação estudada, e uma análise mais detalhada do padrão de disseminação poderia contribuir com o planejamento das ações de controle. Essa hipótese, contudo, carece de verificação.

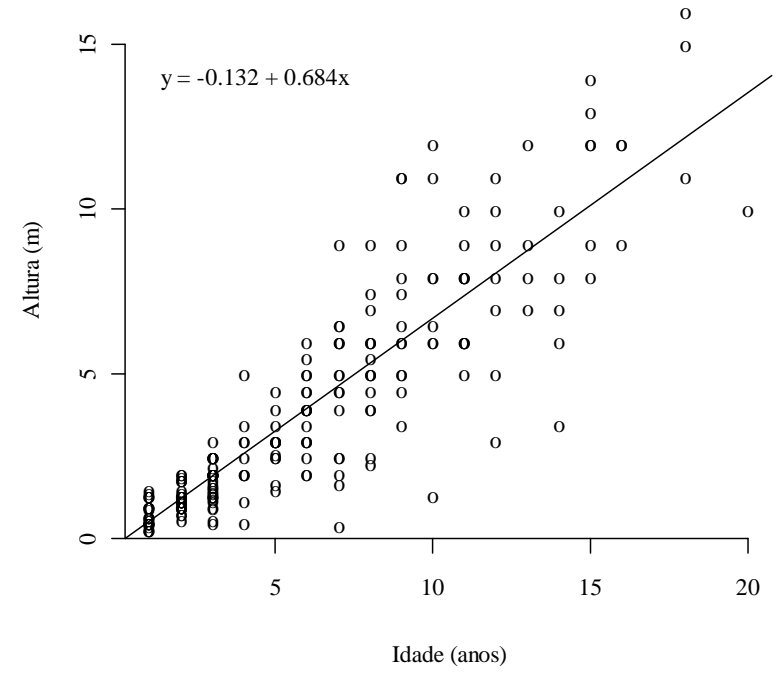

Figura 2. Regressão linear correlacionando idade e altura das árvores de Pinus taeda no conjunto dos morros Tucum, Camapuã e Camacuã, Parque Estadual do Pico Paraná. y = -0.13166 + 0.6838*x; p<0,001.

Figure 2. Linear regression correlating age and height of Pinus taeda plants invading Tucum, Camapuã and Camacuã mountains, in Pico Paraná State Park. $y=-0.13166+0.6838 * x ; p<0,001$.

Foram encontradas plantas em fitofisionomias subarbustivas (39,5\%), em fitofisionomia campestre $(56,72 \%)$, em afloramentos rochosos $(3,36 \%)$ e em fitofisionomia florestal $(0,42 \%)$. Embora não seja possível, com os dados apresentados neste trabalho, determinar se as fitofisionomias existentes nos campos de altitude apresentam diferentes níveis de suscetibilidade à invasão e nem que Pinus taeda tenha capacidade diferenciada para invadir cada uma dessas fitofisionomias, pode-se afirmar que nenhuma delas apresenta barreiras efetivas ao estabelecimento da espécie. Embora essas diferenças de valores sejam resultantes de amostragem e possam não refletir maior ou menor capacidade de invasão nas diferentes fitofisionomias, o gênero Pinus é predominantemente heliófilo e sabidamente invade ecossistemas abertos, clareiras e áreas desmatadas.

\section{Ação de manejo}

No total, foram removidas 2.390 plantas de Pinus taeda numa área de 166 ha em 20 dias de trabalho, com uma equipe de 4 pessoas, totalizando 640 horas de trabalho (Tabela 1). O rendimento variou entre 1 e 12 hectares por dia, em função da densidade de indivíduos por hectare, do tipo de vegetação e da condição de acesso (relevo e existência de trilhas).

Em áreas com uma média de 400 pínus/ha foi possível cobrir apenas um hectare por dia. Em áreas com 10 pínus por hectare, porém, foram cobertos até 10 hectares. A eliminação de plantas localizadas em pontos de difícil acesso pode, porém, tomar muito tempo e reduzir significativamente esse valor médio, especialmente à medida que a invasão avança livre de qualquer ação de controle.

Várias outras medidas são sugeridas para o controle da invasão de Pinus, entre as quais está o uso de fogo, o anelamento e a utilização de herbicidas sem o corte da planta (CUEVAS, 2005). A escolha do uso de um ou outro está relacionada às características do terreno, à necessidade de evitar impactos da derrubada sobre vegetação nativa, à densidade e tamanho dos indivíduos e ao ambiente onde ocorre a invasão. Nesse sentido, do ponto de vista logístico e econômico, o corte mecânico aqui utilizado se mostrou adequado e suficiente. 
Tabela 1. Custos de controle de Pinus taeda nos campos de altitude da Serra do Mar estimados a partir do projeto.

Table 1. Control costs for Pinus taeda in the mountain top grasslands of Serra do Mar obtained from the project.

\begin{tabular}{lcc}
\hline Item de custo & Unidade & Valor $(\mathbf{R} \$)$ \\
\hline Total do trabalho & 640 horas, 20 dias & $33.000,00$ \\
Médio com equipe de 4 pessoas & Hectare & 199,00 \\
Homem & Dia & 183,00 \\
Alimentação & Homem/dia & 10,00 \\
Transporte e combustível para veículo e motosserra & Dia & 20,00 \\
\hline
\end{tabular}

Ficou claro também que, embora o esforço do controle aumente com o tempo, ele não cresce de forma proporcional à invasão, pois, considerando-se os dados mínimos e máximos de densidade e custo por hectare obtidos neste trabalho, no mesmo tempo em que a densidade de plantas invasoras aumentaria 40 vezes (de 10 plantas.ha $^{-1}$ para 400 plantas.ha $^{-1}$ ), o custo de controle aumentaria 10 vezes (de 10 ha.dia $^{-1}$ para 1 ha.dia $\left.{ }^{-1}\right)$.

Efeitos da presença e do manejo de Pinus taeda sobre a riqueza e abundância de espécies nativas

No total dos três tratamentos foram encontradas 60 espécies nativas (Tabela 2). As formas de vida mais frequentes foram herbáceas (60\%), seguidas de arbustivas (28\%), arbóreas (7\%) e lianas (5\%). A família com maior riqueza foi Asteraceae, com 15 espécies, sendo Baccharis trimera Less. e Stevia clausenii Sch. Bip. ex Baker. as mais expressivas nos três tratamentos. As duas espécies da família Bromeliaceae encontradas foram detectadas somente no tratamento TESTEMUNHA. As espécies Lobelia camporum Pohl. (Campanulaceae) e Gaylussacia brasiliensis Meisn. (Ericaceae) foram as mais representativas dos três tratamentos, principalmente no MANEJO, com frequência observada de $36 \%$ e 46\%, respectivamente. Hesperozygis nitida Epling (Lamiaceae) destacou-se pela elevada frequência (94\%) no tratamento MANEJO.

Onze espécies apareceram em todos os tratamentos, em especial Danthonia sp. e Andropogon macrothrix Trinius. (ambas da família Poaceae). No tratamento COM PINUS foram registradas 13 espécies exclusivas, no tratamento MANEJO 6 espécies e no TESTEMUNHA 19 espécies exclusivas. Algumas espécies, como Grazielia sp. (Asteraceae), Rumohra adiatiformis Ching. (Dryopteridaceae), Tibouchina reitzii Brade. (Melastomataceae), Andropogon macrothrix Trin. (Poaceae) e Aulonemia finbriatifolia L. G. Cark. (Poaceae), apresentaram maior frequência no tratamento COM PINUS do que nos outros tratamentos (Tabela 2).

A comparação dos parâmetros da vegetação entre os tratamentos mostrou que houve diferença na riqueza média entre os tratamentos $(\mathrm{F}=25,52 ; \mathrm{p}<0,01)$. No tratamento TESTEMUNHA (ausência de pínus) registrou-se riqueza superior ao tratamento COM PINUS, e neste, riqueza superior ao tratamento MANEJO (Figura 3a). A cobertura vegetal total (todas as formas de vida) foi maior na TESTEMUNHA, seguida de MANEJO e COM PINUS ( $F=61,00 ; p<0,01$; Figura 3b). A cobertura de espécies herbáceas diferiu entre os tratamentos $(F=46,30 ; \mathrm{p}<0,01)$, com as médias do TESTEMUNHA superiores a MANEJO e COM PINUS (Figura 3c). Não houve diferenças entre os tratamentos para a cobertura de espécies arbustivo-arbóreas ( $\mathrm{F}=2,31 ; \mathrm{p}>0,05$; Figura 3d).

A partir das análises de correlações realizadas no tratamento COM PINUS, verificou-se que a cobertura de acículas está inversamente relacionada à riqueza de espécies herbáceas $(r=-0,43 ; p<0,01)$, potencialmente indicando interferência das acículas sobre a sobrevivência de espécies nativas. Da mesma forma, no tratamento MANEJO houve relação inversa entre a cobertura de acículas e a cobertura de herbáceas $(r=-0,77 ; p<0,01)$ e entre a presença de troncos cortados e a cobertura herbácea $(r=-0,30$; $\mathrm{p}<0,04)$, embora essa correlação seja fraca. As relações entre as coberturas de acículas e troncos e a riqueza e cobertura de espécies arbustivo-arbóreas não foram significativas ( $p>0,05)$.

Decorridos dez meses das ações de controle, observou-se que o controle mecânico de Pinus taeda por corte raso favoreceu a retomada da cobertura vegetal nativa, mas não a riqueza de espécies presentes nas áreas invadidas. É provável que dez meses não seja tempo suficiente para que os valores de cobertura e riqueza se estabilizem após uma intervenção de manejo seguida por anos de invasão biológica. 
Tabela 2. Lista de espécies amostradas com suas respectivas frequências (\% de parcelas), em cada tratamento, na Serra do Ibitiraquire, Paraná. Hábito: Her = herbáceo; Arb = arbustivo; Arv = arbóreo; Lia = lianescente.

Table 2. Sampled species and their frequency ( $\%$ of presence on quadrats). Her $=$ herbaceous, Arb $=$ shrub, Arv $=$ tree, and Lia $=$ climber.

\begin{tabular}{|c|c|c|c|c|c|}
\hline \multirow{2}{*}{ Família } & \multirow{2}{*}{ Espécie } & \multirow{2}{*}{ Hábito } & \multicolumn{3}{|c|}{ Tratamento (\% de parcelas) } \\
\hline & & & Pinus & Manejo & Testemunha \\
\hline \multirow[t]{15}{*}{ Asteraceae } & Austroeupatorium sp. & Her & 4 & 0 & 0 \\
\hline & Austroeupatorium sp. & Her & 6 & 0 & 0 \\
\hline & Baccharis nummularia Heering ex. Malme & Arb & 0 & 0 & 8 \\
\hline & Baccharis pauciflosculosa DC. & Arb & 4 & 2 & 0 \\
\hline & Baccharis sp. & Arb & 0 & 4 & 16 \\
\hline & Baccharis trimera (Less.) & Her & 36 & 48 & 68 \\
\hline & Baccharis uncinella DC. & Arb & 2 & 12 & 0 \\
\hline & $\begin{array}{l}\text { Campovassouria cruciata (Vell.) R.M. } \\
\text { King \& H. Rob. }\end{array}$ & Arb & 0 & 8 & 0 \\
\hline & Disynaphia sp. & Arb & 0 & 2 & 0 \\
\hline & Grazielia sp. & Her & 36 & 2 & 0 \\
\hline & Mikania sp. & Lia & 2 & 0 & 0 \\
\hline & Senecio sp. & Arb & 6 & 22 & 62 \\
\hline & Stevia clausenii Sch. Bip. ex Baker & Her & 36 & 36 & 68 \\
\hline & Symphyopappus sp. & Arb & 0 & 0 & 2 \\
\hline & $\begin{array}{l}\text { Vernonanthura montevidensis (Spreng.) } \\
\text { H. Rob. }\end{array}$ & Arb & 6 & 0 & 0 \\
\hline Bignoniaceae & Tabebuia catarinensis A. Gentry & Arv & 0 & 0 & 30 \\
\hline Blechnaceae & Blechnum cf. schomburgkii (K1.) C. Chr. & Her & 0 & 2 & 6 \\
\hline \multirow[t]{2}{*}{ Bromeliaceae } & Dyckia reitzii L.B. Smith & Her & 0 & 0 & 14 \\
\hline & Bromeliaceae 1 & Her & 0 & 0 & 32 \\
\hline Caesalpiniaceae & $\begin{array}{l}\text { Senna multijuga (L. Rich) H.S. Irwin \& R. } \\
\text { Barneby }\end{array}$ & Arv & 2 & 0 & 0 \\
\hline Campanulaceae & Lobelia camporum Pohl. & Her & 14 & 36 & 30 \\
\hline Commelinaceae & Tradeschantia fluminensis Vell. & Her & 6 & 0 & 0 \\
\hline Cyperaceae & Cyperaceae 1 & Her & 0 & 0 & 12 \\
\hline Dryopteridaceae & Rumohra adiatiformis (G. Forst.) Ching. & Her & 32 & 4 & 0 \\
\hline Ericaceae & Gaylussacia brasiliensis Meisn. & Arb & 6 & 46 & 16 \\
\hline Eriocaulaceae & Eriocaulon sp. & Her & 0 & 0 & 52 \\
\hline Iridaceae & Gelasine coerula (Vell.) Ravenna & Her & 0 & 0 & 8 \\
\hline Lamiaceae & Hesperozygis nitida (Bentham) Epling. & Her & 0 & 94 & 46 \\
\hline \multirow[t]{2}{*}{ Lycopodiaceae } & Lycopodium clavatum $\mathrm{L}$. & Her & 0 & 0 & 8 \\
\hline & $\begin{array}{l}\text { Lycopodium thyoides Humb. \& Bonpl. Ex } \\
\text { Willd. }\end{array}$ & Her & 0 & 4 & 2 \\
\hline \multirow[t]{3}{*}{ Melastomataceae } & Leandra sp1. & Her & 38 & 10 & 52 \\
\hline & Leandra sp2. & Her & 4 & 0 & 0 \\
\hline & Tibouchina reitzii Brade. & Arv & 48 & 10 & 34 \\
\hline \multirow[t]{2}{*}{ Myrsinaceae } & $\begin{array}{l}\text { Myrsine altomontana M.F. Freitas \& L.S. } \\
\text { Kinoshita }\end{array}$ & Arv & 2 & 0 & 0 \\
\hline & Myrsine coriacea Sieber ex. A. DC. & Arb & 4 & 0 & 0 \\
\hline \multirow[t]{2}{*}{ Myrtaceae } & Myrceugenia ovata O. Berg. & Arb & 2 & 0 & 0 \\
\hline & Myrtaceae 1 & Arb & 2 & 0 & 0 \\
\hline Onagraceae & Fucksia regia (Vell.) & Arb & 0 & 0 & 2 \\
\hline \multirow[t]{2}{*}{ Orchidaceae } & Habenaria parviflora Lindl. & Her & 0 & 0 & 6 \\
\hline & Orchidaceae 1 & Her & 8 & 0 & 0 \\
\hline \multirow[t]{3}{*}{ Poaceae } & Andropogon macrothrix Trinius. & Her & 68 & 36 & 22 \\
\hline & Aulonemia finbriatifolia L.G. Cark. & Her & 80 & 6 & 0 \\
\hline & Danthonia sp. & Her & 88 & 50 & 92 \\
\hline
\end{tabular}

FLORESTA, Curitiba, PR, v. 41, n. 1, p. 123-134, jan./mar. 2011. 


\begin{tabular}{llllll}
\hline Proteaceae & Roupala montana Aubl. var. paraensis & Arb & 8 & 12 & 8 \\
& (Sleumer) K.S. Edwards & Her & 0 & 0 & 2 \\
Pteridaceae & Doryopteris crenulans (Fée) H. Christ. & Arb & 0 & 4 & 0 \\
Sapindaceae & Cupania vernalis Camb. & Lia & 0 & 2 & 2 \\
Smilacaceae & Smilax campestris Griseb. & Her & 12 & 18 & 6 \\
Indeterminada & Indeterminada 1 & Arb & 2 & 0 & 0 \\
& Indeterminada 2 & Her & 0 & 0 & 4 \\
& Indeterminada 3 & Her & 0 & 0 & 2 \\
& Indeterminada 4 & Her & 0 & 0 & 8 \\
& Indeterminada 5 & Lia & 0 & 6 & 14 \\
& Indeterminada 6 & Her & 0 & 0 & 16 \\
& Indeterminada 7 & Her & 0 & 0 & 2 \\
& Indeterminada 8 & Her & 0 & 0 & 2 \\
& Indeterminada 9 9 & Her & 0 & 2 & 0 \\
& Indeterminada 10 10 & Her & 0 & 2 & 0 \\
& Indeterminada 11 & Her & 0 & 8 & 0 \\
\hline
\end{tabular}

A)

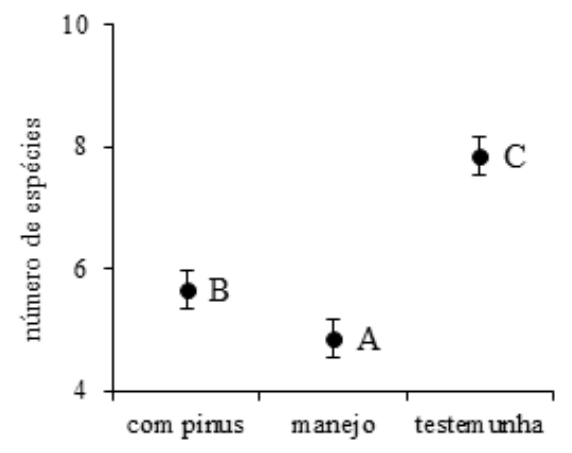

C)

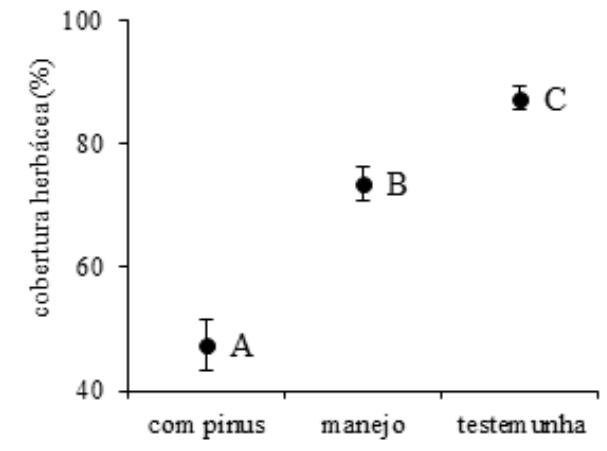

B)

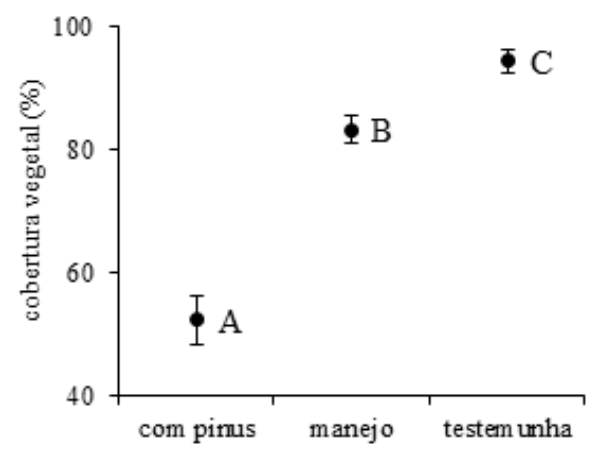

D)

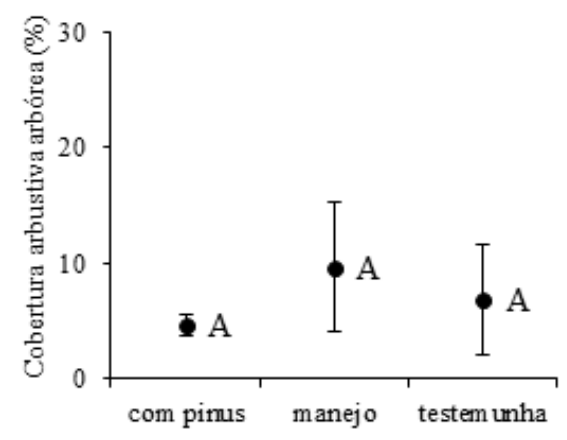

Figura 3. Valores médios dos parâmetros da vegetação dos três tratamentos (COM PINUS, MANEJO, TESTEMUNHA), na área do projeto. (A) riqueza; (B) cobertura vegetal; (C) cobertura de espécies herbáceas; (D) cobertura de espécies arbustivo-arbóreas. Figuras apresentam diferenças nas escalas. Médias seguidas pelas mesmas letras não diferem estatisticamente pelo teste de Tukey-Kramer.

Figure 3. Mean values for all the treatments (COM PINUS, MANEJO e TESTEMUNHA) in the project area. (A) richness, (B) plant coverage, (C) herbaceous species coverage, and (D) shrub and tree species coverage. Figures have different scales. Mean values followed by the same letters are statistically equal according to Tukey-Kramer's test. 
Observou-se maior riqueza de espécies nas áreas livres de pínus (tratamento TESTEMUNHA) do que nas áreas dos demais tratamentos. Esse resultado era esperado, uma vez que a presença de espécies invasoras tende a alterar a composição de espécies nativas em áreas naturais (RICHARDSON, 1998). Por outro lado, a maior riqueza de espécies nas áreas invadidas e sem manejo (COM PINUS) em relação às áreas sob manejo (MANEJO) é um resultado não esperado. Como não houve mensuração de riqueza e diversidade antes das intervenções para remoção de pínus, depreende-se que esse resultado seja mais um fator de variação ambiental natural das áreas aleatoriamente selecionadas para amostragem do que uma decorrência da remoção de pínus ou do impacto do manejo. Não é possível afirmar que houve maior impacto em função da retirada de pínus, pois talvez a área já estivesse mais empobrecida em função do acúmulo de acículas e do sombreamento resultantes da presença das plantas invasoras na área. Somente um monitoramento de longo prazo nessas áreas poderá esclarecer essa situação e fornecer uma interpretação mais precisa. Ainda assim, o impacto da intervenção no ambiente deve ser considerado nas ações de restauração ambiental, no sentido de ajudar a estabelecer a necessidade de plantios de restauração ou de práticas de controle de erosão.

As espécies Tabebuia catarinensis e Habenaria parviflora, consideradas endêmicas (PORTES et al., 2001), foram registradas apenas nas áreas livres de invasão (TESTEMUNHA), o que sugere um possível efeito negativo da presença de $P$. taeda para essas espécies. Hesperozygis nitida contribuiu sobremaneira para a cobertura vegetal nas áreas sob manejo (MANEJO) e possivelmente trata-se de espécie oportunista ou de sucessão inicial, cujo crescimento ou propagação foi acelerado logo após o corte de P. taeda. No entanto, espécies com esse comportamento tendem a ter as suas densidades diminuídas com o tempo (HARPER, 1977), sendo balanceadas com o aumento das densidades de outras espécies.

As diferenças na cobertura vegetal entre os tratamentos seguem um padrão esperado, havendo maior média de cobertura nas áreas livres de pínus (TESTEMUNHA) em relação às áreas sob manejo (MANEJO) e deste em relação às áreas invadidas sem manejo (COM PINUS). Esses resultados denotam que os efeitos negativos normalmente associados à presença de espécies de Pinus refletem na cobertura vegetal nativa (RICHARDSON, 1998; ZILLER, 2000). Entre os possíveis fatores, estão o empobrecimento do solo (DICK et al., 2007) e principalmente o sombreamento promovido pela presença de indivíduos adultos de pínus, afetando a assimilação de carbono e, consequentemente, a cobertura vegetal heliófila (GUREVITCH et al., 2006). Embora a cobertura no tratamento MANEJO esteja sendo muito caracterizada pela alta abundância de Hesperozygis nitida, os resultados sugerem efeitos positivos da remoção de Pinus taeda sobre a cobertura vegetal de espécies nativas.

A cobertura de acículas também tende a influenciar negativamente a riqueza de espécies, o que se reflete nos valores elevados obtidos dessas correlações. Esse efeito parece ser maior em plantas herbáceas. Alguns autores propõem que as acículas de pínus apresentam efeitos alelopáticos, inibindo a germinação e/ou estabelecimento de outras espécies (FERREIRA; AQUILA, 2000; AZEVEDO et al., 2007). No tratamento MANEJO, à medida que as árvores foram cortadas e derrubadas, a quantidade de acículas no solo aumentou, sendo este mais um possível fator de influência para a menor riqueza nas áreas desse tratamento. De fato, já foi verificado que a recuperação da vegetação nativa sob restos de pínus cortados apresenta um retardo devido ao acúmulo de acículas, efeito que é máximo no momento do corte e que diminui com o passar do tempo (DISPIGNO; ZALBA, 2003).

\section{CONCLUSÕES}

- Todas as fitofisionomias dos campos de altitude da Serra do Mar do Paraná são suscetíveis à invasão biológica de Pinus taeda, espécie que apresenta taxa de crescimento em altura de $0,7 \mathrm{~m}$ por ano mesmo em um ambiente com condições adversas. Quanto ao manejo da espécie exótica invasora, o método de controle mecânico por corte raso causou impacto inicialmente negativo, diminuindo a riqueza de espécies nativas, porém aumentou a cobertura vegetal no tratamento MANEJO. Sendo assim, conclui-se que o período de 10 meses após corte raso é insuficiente para uma avaliação consistente sobre o método de controle mecânico, já que há tendência à regeneração de outras espécies em prazo mais longo.

- As experiências de manejo apresentadas podem ser utilizadas como base para aprimorar e planejar novas ações de controle de espécies exóticas invasoras no local, evitando dessa forma a reinvasão das 
áreas trabalhadas e assegurando a conservação dos campos de altitude nos topos de morro da Serra do Mar. A necessidade de seguir com o trabalho de controle é premente, pois, caso nada mais seja feito, haverá reinvasão das áreas já trabalhadas a partir do banco de sementes ou de outras sementes trazidas pelo vento dos plantios florestais próximos. O manejo adequado dessas plantações precisa incorporar a responsabilidade pelo controle de pínus nas áreas altas da Serra do Mar.

- O presente estudo evidencia o caráter invasor de Pinus taeda nos campos de altitude da Serra do Mar e os efeitos negativos que essa invasão pode trazer à biodiversidade local. A riqueza e o percentual de cobertura do solo por plantas nativas são afetados negativamente pela presença de pínus. Como a invasão aumenta gradativamente e se agrava com o passar do tempo na ausência de medidas de controle (ZILLER, 2000) e a recuperação do ambiente após ações de manejo e controle não é imediata, é sempre necessário verificar a necessidade de se estabelecerem ações de restauração e controle de erosão.

- O grande número de espécies exclusivas em cada tratamento também indica a necessidade de cautela na interpretação dos dados e mais tempo de avaliação para que seja possível concluir sobre a consistência e a persistência dos padrões encontrados neste estudo, uma vez que podem ser fruto de uma heterogeneidade existente prévia à invasão de pínus.

\section{AGRADECIMENTOS}

À Fundação O Boticário de Proteção à Natureza, pelo patrocínio; ao Instituto Ambiental do Paraná, pelo apoio; ao engenheiro florestal M.Sc. Marcelo Brotto, pela ajuda na identificação das espécies; a Maria Fernanda M. A. Barros, Flávio Krüger, Tiago Machado, Jovani, Diogo Hungria e Jean, pela ajuda no trabalho de campo; e à Prof. Dra. Márcia Marques, por importantes sugestões nas primeiras versões do trabalho. Os autores também agradecem a dois revisores anônimos, por importantes sugestões ao manuscrito.

\section{REFERÊNCIAS}

ABREU, G. A. Os impactos ambientais da expansão das monoculturas de árvores exóticas e a sustentabilidade de comunidades rurais do Rio Grande do Sul, Brasil. Porto Alegre. 37 p. Disponível em <http://www.defesabiogaucha.org/textos/texto17.pdf〉. Acesso em 1 de fevereiro de 2009. 2006.

ANDRADE, A. S. Qualidade da madeira, celulose e papel em Pinus taeda L.: influência da idade e classe de produtividade. Dissertação de Mestrado. Curitiba: Universidade Federal do Paraná. 2006.

APG II. Angiosperm Phylogeny Group II. Botanical Journal of the Linnean Society, v. 141, p. 399-436, 2003.

AZEVEDO, V. K.; BRAGA, T. V. S.; GOI, S. R. Efeito alelopático de extrato de Eucalyptus citriodora e Pinus elliottii sobre a germinação de Lactuca sativa L. (alface). In: ROSSO, S. (org.). VIII Congresso Brasileiro de Ecologia do Brasil, Anais. Caxambú, Minas Gerais, 2007.

BALDANZI, G.; RITTERSCHOFER, F. O.; REISSMANN, C. B. Procedências de Pinus sp. adaptadas às condições ecológicas dos planaltos sulinos. Revista Floresta, v. 5, n. 1, p. 31-34, 1974.

BECHARA, F. C. Restauração ecológica de restingas contaminadas por Pinus no Parque Florestal do Rio Vermelho, Florianópolis, SC. Dissertação de Mestrado. Florianópolis: Universidade Federal de Santa Catarina, 2003.

CUEVAS, Y. A. Plan de manejo de Pinus halepensis para el Parque Provincial Ernesto Tornquist (Buenos Aires). Dissertação de Mestrado. Córdoba, Argentina: Universidad Nacional de Córdoba, 2005.

DAVIS, M. A. Invasion biology. Oxford, USA: Oxford University Press, 2009.

DICK, D. P.; DALMOLIN, R. S. D.; LEITE, S. B. Impacto da introdução de Pinus nas características químicas e na composição da matéria orgânica de Neossolos de Campos de Cima da Serra, RS. In: XXXI Congresso Brasileiro de Ciência do Solo, Anais, v. 1, p. 236-236, 2007. Porto Alegre, Rio Grande do Sul. 
DISPIGNO, L.; ZALBA, S. M. Cambios en las comunidades vegetales luego del control de ejemplares aislados de Pinus halepensis. San Luis, Argentina: Livro de resumos XXIX Jornadas Argentinas de Botánica. 2003.

FERREIRA, A. G.; AQUILA, M. E. A. Alelopatia: uma área emergente da ecofisiologia. Revista Brasileira de Fisiologia Vegetal, v. 12, p. 175-204, 2000.

GUREVITCH, J.; SCHEINER, S. M.; FOX, G. A. The ecology of plants. Sunderland, USA: Sinauer Associates, 2006.

HARPER, J. L. Population biology of plants. Journal of Applied Ecology, v. 15, n. 2, p. 642-644, 1977.

HIGGINS, S. I.; RICHARDSON, D. M. Pine invasions in the southern hemisphere: modelling interactions between organism, environment and disturbance. Plant Ecology, v. 135, p. 79-93, 1998.

IAPAR. Cartas climáticas do estado do Paraná. Londrina, 1994. 49 p.

LEDGARD, N. The spread of lodgepole pine (Pinus contorta Dougl.) in New Zealand. Forest Ecology and Management, v. 141, p. 43-57, 2001.

MAHMOUD, A. G. E.; VIRILLO, C. B.; RIBEIRO, D. B.; ALCÂNTARA, S. F. Invasão de Pinus elliottii em um fragmento de cerrado em Itirapina-SP. Disponível em http://www.ib.unicamp.br/profs/fsantos/ relatorios/bt791r2a2003.pdf. Acesso em 1 de fevereiro de 2009. 2003.

MOCOCHINSKI, A. Y. Campos de altitude na Serra do Mar paranaense: aspectos florísticos e estruturais. Dissertação de Mestrado. Curitiba: Universidade Federal do Paraná, 2006.

MOCOCHINSKI, A. Y.; SCHEER, M. B. Campos de altitude na Serra do Mar paranaense: aspectos florísticos. Floresta, v. 38, n. 4, p. 625-640, 2008.

MOONEY, H. A.; CLELAND, E. E. The evolutionary impact of invasive species. Colloquium. Proceedings of the National Academy of Sciences, v. 98, n. 10, p. 5446-5451, 2001.

MÜLLER-DUMBOIS, D.; ELLENBERG, H. Aimms and methods of vegetation ecology. New York: John Wiley \& Sons. 1974.

NATHAN, R.; KATUL, G. G.; HORN, H. S.; THOMAS, S. M.; OREN, R.; AVISSAR, R.; PACALA, S. W.; LEVIN, S. A. Mechanisms of long-distance dispersal of seeds by wind. Nature, v. 418, p. 409-413, 2002.

PIVELLO, V. R. Invasões biológicas no cerrado brasileiro: efeitos da introdução de espécies exóticas sobre a biodiversidade. INFO 33. ECOLOGIA. Disponível em <http://www.ecologia.info/cerrado.htm〉. Acesso em 2 de fevereiro de 2009. 2005.

PORTES, M. C.; GALVÃO, F.; KOEHLER, A. Caracterização florística e estrutural de uma floresta ombrófila densa altomontana do morro do Anhangava, Quatro Barras, PR. Floresta, v. 31, n. 1-2, p. 2231, 2001.

PYŠEK, P.; RICHARDSON, D. M. Invasive plants. In: JØRGENSEN, S. E.; FATH, B. D. (eds.) Encyclopedia of Ecology: Ecological Engineering, v. 3, p. 2011-2020. Oxford: Elsevier. 2008.

RICHARDSON, D. M. Forestry trees as invasive aliens. Conservation Biology, v. 12, n. 1, p. 18-26, 1998.

RICHARDSON, D. M.; PYŠEK, P.; REJMÁNEK, M.; BARBOUR, M. G.; PANETTA, F. D.; WEST, C. J. Naturalization and invasion of alien plants: concepts and definition. Diversity and Distribution, v. 6, n. 93-107, 2000.

RICHARDSON, D. M.; VAN WILGEN, B. W.; NUÑEZ, M. A. Alien conifer invasions in South America: short fuse burning? Biological Invasions, v. 10, p. 573-577, 2008.

SAFFORD, H. D. Brazilian Paramos I. An introduction to the physical environment and vegetation of the campos de altitude. Journal of Biogeography, v. 26, p. 693-712, 1999.

SHIMIZU, J. Y. Pinus na silvicultura brasileira. Revista da Madeira, v. 16, n. 99, p. 4-14, 2006. 
SIMÃO, C. Caracterização florística e espectro biológico de refúgios vegetacionais altomontanos no morro Anhangava, Parque Estadual Serra da Baitaca, Paraná. Dissertação de Mestrado. Curitiba: Universidade Federal do Paraná. 2008.

SIMBERLOFF, D.; NUÑEZ, M. A.; LEDGARD, N. J.; PAUCHARD, A.; RICHARDSON, D. M.; SARASOLA, M.; VAN WILGEN, B. W.; ZALBA, S. M.; ZENNI, R. D.; BUSTAMANTE, R.; PEÑA, E.; ZILLER, S. R. Spread and impact of introduced conifers in South America: Lessons from other southern hemisphere regions. Austral Ecology, no prelo, 2010.

TRAMUJAS, A. P. A vegetação dos campos de altitude na região do Ibitiraquire - Serra do Mar municípios de Antonina, Morretes e Campina Grande do Sul, Paraná. Dissertação de Mestrado. Curitiba: Universidade Federal do Paraná. 2000.

VASHCHENKO, Y.; FAVARETTO, N.; BIONDI, D. Fragilidade ambiental nos picos Camacuã, Camapuã e Tucum, Campina Grande do Sul, PR. Revista Floresta, v. 37, n. 2, p. 201-215, 2007.

ZALBA, S. M.; CUEVAS, Y. A.; BOÓ, R. M. Invasion of Pinus halepensis Mill. following a wildfire in an Argentine grassland nature reserve. Journal of Environmental Management, v. 88, p. 539-546, 2008.

ZAR, J. H. Biostatiscal analysis. New Jersey, USA: Northern Illinois University, Prentice-Hall, 1999.

ZILLER, S. R. A estepe gramíneo-lenhosa no segundo planalto do Paraná: diagnóstico ambiental com enfoque à contaminação biológica. Tese de Doutorado. Curitiba: Universidade Federal do Paraná. 2000.

Os processos de degradação ambiental originados por plantas invasoras. Revista Ciência Hoje, v. 178, p. 77-79, 2001. 